\title{
Is operations research really research?
}

\author{
NJ Manson* \\ Received: 2 October 2006; Accepted: 1 November 2006
}

\begin{abstract}
This paper takes a philosophical look at the Research in Operations Research. First, the questions "What is Research?" and "What is Operations Research?" are discussed. Next, the paper discusses why it is important to have a clear definition of research, especially in academia. The paper then discusses a research paradigm called 'Design Research'. Design Research is defined and compared with other research paradigms. Seven guidelines for understanding, executing, and evaluating Design Research are presented. As examples, three recently published papers on Operations Research are evaluated using these guidelines. Finally, conclusions are presented discussing why it can be advantageous to understand, execute and evaluate Operations Research projects within the Design Research paradigm.
\end{abstract}

Key words: Philosophy, Design Research, Operations Research, research paradigm.

\section{Introduction}

Although Quantitative methods have been used to help make decisions for centuries, the discipline of Operations Research (OR) really began in 1937. In this year, EC Williams, a young physicist from Birmingham University, was recruited to conduct research into the operational aspects of the newly developed radar systems, and was given the title of Operations Researcher. This designation was then adopted by a number of small teams, who gathered together from 1939 onwards to assist British military decision making during World War II [6].

But, is the practice of Operations Research really research?

This paper will begin to answer this question by discussing what research is, why it is done, and the ways in which it can be carried out. The nature of OR will then be described, including a brief survey of recent ORiON issues. Next, the question of why this matters will be discussed. Thereafter, a research perspective called Design Research, or Design Science, will be presented, and compared with more traditional perspectives. The next section will discuss some recent examples of papers from ORiON in the framework of Design Research. Finally, conclusions are presented discussing why it may be advantageous to understand, execute and evaluate OR projects within the Design Research paradigm.

\footnotetext{
${ }^{*}$ School of Information Technology, Monash South Africa, Private bag X60, Roodepoort, 1725, Republic of South Africa, email: neil.manson@infotech.monash.edu
} 


\section{What is research?}

The Collins Paperback English Dictionary defines research as a "systematic investigation to establish facts or collect information on a subject [14]." Vaishnavi and Kuechler [23] define research as "an activity that contributes to the understanding of a phenomenon." By these definitions, reading a first-year textbook would, hopefully, be research for a student. Vaishnavi and Kuechler [23] go on to define a phenomenon as "a set of behaviours of some entity(ies) that is found interesting by the researcher or by a group," and understanding as "knowledge that allows prediction of the behaviour of some aspect of the phenomenon." Academic research usually includes the idea that research adds something that is, in some sense, new to the body of knowledge. The Office of Research and Innovation of Edith Cowan University state that research "comprises creative work undertaken on a systematic basis in order to increase the stock of knowledge, including knowledge of man (sic), culture and society, and the use of this stock of knowledge to devise new applications" [17]. Other concepts that are associated with academic research include rigour, relevance and a systematic approach. These are the kinds of things that journal reviewers look for when trying to evaluate the quality of research.

Research is often divided into Basic and Applied research. Wikipedia [26] states that "Basic research (also called fundamental or pure research) has as its primary objective the advancement of knowledge and the theoretical understanding of the relations among variables. It is exploratory and often driven by the researcher's curiosity, interest, or hunch. It is conducted without any practical end in mind, although it may have unexpected results pointing to practical applications." On the other hand, "Applied research is done to solve specific, practical questions; its primary aim is not to gain knowledge for its own sake" $[26]$.

\subsection{Why do we do research?}

We do research to gain understanding. There are three main reasons why we might wish to gain understanding. Firstly, because humans are more curious than cats. We would do research to satisfy our curiosity, even if there were no practical application for the understanding obtained. Secondly, as mentioned above, we do research in order to predict the behaviour of an entity. An example of this would be seismic research that helps us predict the occurrence of earthquakes. This has practical value in that it may allow us to save lives, even though we cannot actually change the phenomenon. Thirdly, we do research in order to change the behaviour of an entity. If we can predict an entity's behaviour, then we can also predict the effect on that behaviour if we change the entity in some way. A good example of this is medical research, where we try to understand the processes that cause a disease, so that we can prevent or cure it.

\subsection{What do we do research on?}

What kinds of phenomena do we do research on? Simon [20] divides the universe into the natural and the artificial. Natural phenomena are those that occur 'naturally' in the world, such as earthquakes, diseases and human behaviour. Artificial phenomena are 
those that are created by man, for the purpose of satisfying man's desires and achieving his goals. Natural Science, or natural research, is concerned with understanding and explaining natural phenomena. The Science of the Artificial [20], also known as Design Science [23], is concerned with man-made, artificial phenomena.

\subsection{Types of research}

If one reads almost any book on how to do research, one will immediately be presented with one of two ways to do research: Quantitative or Qualitative [16, 22]. However, these are just methodologies, or prescriptions of how to do a part of research. Much of the literature on research divides the types of research into Positivist and Interpretivist viewpoints [23], although some authors disagree with this distinction [25]. The viewpoint that is assumed by a particular researcher will affect all of their research, including the methodologies they choose to use. These viewpoints, and their associated methodologies will be discussed in more detail in $§ 5.3$.

\subsection{How do we do research?}

The Natural Science research process is composed of two activities, discovery and justification [9]. Discovery is the process of generating and proposing scientific claims. This process is not well understood, and is inherently creative. Justification is the process of testing the claims for validity. This is usually done by trying to prove the claim false, as a single negative instance can do so, while innumerable positive instances cannot prove a claim true [12]. Most research methodologies are prescriptions of how to gather data and test claims; that is, they are prescriptions for the justification process and say nothing about the discovery process.

\subsection{How do we measure the quality of research?}

The way in which the quality of a particular piece of research is measured depends on the viewpoint that was adopted by the researchers conducting the research. In Natural Science, the measure of claims and theories is their explanatory power. "Good" claims are consistent with observed facts, and provide deep, encompassing and accurate predictions of future observations [12].

\section{What is operations research?}

As with many other applied fields, there are two components to the discipline of OR. There is the practice of the discipline, and there is research into the tools and methods of the discipline. An analogy of this is the practice of medicine. The General Practitioner or Specialist uses their knowledge, experience, tools and methods to diagnose and treat patients. This is not research as they are not adding anything new to the body of medical knowledge, although they may be providing new understanding to the patient. At the same time there are the medical researchers who are doing research to increase their understanding of the human body, and to use that understanding to develop better tools 
and methods. Sometimes an individual will combine practice and research at the same time, but they are still distinct actives. The difference between medicine and OR is that medicine does not claim that the practice is also research in its name!

\subsection{Research into operations research}

Research into OR seeks to advance the practice of OR by various means, including, but not limited to:

- Developing new, or improved, models of various systems.

- Developing new, or improved, algorithms for solving models.

- Developing new, or improved, methodologies.

- Developing new, or improved, tools such as software.

- Increasing the understanding of phenomena that affect the implementation or adoption of OR models and methodologies.

Research that seeks to improve the practice of OR is generally applied research, but it may be considered basic research if the practical application is only potential.

\subsection{Practice of operations research}

The Institute for Operations Research and the Management Sciences (INFORMS) describes OR as "the discipline of applying advanced analytical methods to help make better decisions" [5]. They go on to expand this explanation as follows: "By using techniques such as mathematical modelling to analyse complex situations, operations research gives executives the power to make more effective decisions and build more productive systems" $[5]$.

When a practitioner applies a standard tool, such as linear programming, to solve a problem from a class that is well understood, such as resource allocation, is he conducting research? He is definitely providing new knowledge to the organisation for whom he is solving the problem, but he is not adding anything new to the body of OR knowledge. The author would argue that in the general sense of research as "systematic investigation to establish facts or collect information on a subject [14]", then this is research. However, is it research in the sense of research as "creative work undertaken on a systematic basis in order to increase the stock of knowledge" [17]?

A brief review of 20 abstracts from Volume 52 (2006) of Management Science revealed that $50 \%$ of the published articles were Research into OR. A further $30 \%$ of articles were not OR, but rather articles on Management. Only 20\% of the articles reviewed described projects that could be considered Practice of OR. However, all of these projects approached the research from a Natural Science perspective. They were projects that analysed a particular system in order to gain greater understanding. There appears to be no attempt to build a model, or to 'solve the problem'. This would seem to indicate that, in the eyes of Management Science at least, the practice of OR is not seen as research. 
However, many OR projects blur the line between practice and research. Many times, a project will set out to apply a standard tool to what is thought to be a well understood problem, but during the course of the project it is discovered that this will not work. Additional complexities are discovered that reveal that the problem is not well understood, or that the standard tool is not entirely applicable. This often leads practitioners to go beyond the standard and well understood, and forces them to develop something new. When this happens it is necessary that this 'something new' be made available to other researchers and practitioners, and this is typically done through publication in a journal. However, the question that must be asked is "How do we evaluate the quality of this research?"

\subsection{Survey of ORiON}

In the last five issues of ORiON, from Volume 20(1), 2004 through Volume 22(1), 2006 there were a total of 30 papers published. These articles can be broken down into a number of different types. These types are described in Table 1, which also shows the number of articles of each type. These categories are not distinct as some articles either don't quite fit into a specific category, or overlap more than one.

\begin{tabular}{llc}
\hline Type & Description & Count \\
\hline Review & Literature review. & $1(3 \%)$ \\
\hline Proof & Proofs of theoretical result. & $2(7 \%)$ \\
\hline Theory & $\begin{array}{l}\text { Development of new theory. } \\
\text { Development }\end{array}$ & $\begin{array}{l}\text { Practical problem for which there is no existing theory so } \\
\text { the theory needs to be developed. }\end{array}$ \\
& Extending existing theory. & \\
\hline Analysis & $\begin{array}{l}\text { Analyse a situation to gain understanding, but not to specif- } \\
\text { ically "solve a problem." }\end{array}$ & $9(30 \%)$ \\
\hline Case Study & $\begin{array}{l}\text { Description of the application of O.R. to solve a problem for } \\
\text { a client, but without explicitly developing any new theory. }\end{array}$ & $11(37 \%)$ \\
\hline
\end{tabular}

Table 1: Types of Articles in ORiON, Volumes 20(1) to 22(1).

As may seen from Table 1, the majority of papers were case studies, that is, descriptions of the practice and implementation of OR. The next largest group of papers were analysis papers. These papers were either an analysis of some situation, without any attempt to 'solve the problem,' or were an analysis of some theory. The objective of these articles is to provide a greater understanding of the problem being investigated, in a Natural Science way. The third largest group include those papers that set out to develop new theory. The fourth largest group were two papers that presented proofs of mathematical theorems. The last group was a single paper that presented a literature review, and a discussion of the OR tools necessary for the logistician.

The articles that develop new theory, or present mathematical proofs are clearly research that seeks to improve the practice of OR. The analysis papers are also research as they 
seek to increase the understanding of various systems. The review paper provides a useful review and description of OR tools, although it does not add any new knowledge to the "stock of knowledge" [17]. But what about the largest group of Case Study papers? Are these research?

\section{Why do we care what it is called?}

The practitioner of OR probably does not care whether the work he does is called 'Research' or not, and it is not necessary that he should care. His job is to provide answers to his client. If he does this effectively and efficiently, he will earn a good reputation as a practitioner, and will be paid accordingly.

However, for those who work in academia, things are a little more complicated. Academics earn their reputation, and have their performance judged on the quality of their research. However, many academics are also practitioners, in that they consult to clients in addition to their academic responsibilities. Most universities encourage this consultation, up to a point, as it helps to keep the academics in touch with the 'real' world, and allows the academics to supplement their salaries. For these academics it is of great advantage if their consulting work can also be recognised as high-quality research. It is thus necessary that there is clear understanding of the perspective that is being used when OR projects are presented as research, and clear guidelines on how such research should be evaluated.

OR is applied to organisations, which are, in Simon's words, "Artificial" [20]. Thus Natural Research cannot be applied and neither the Positivist nor the Interpretivist perspectives are appropriate for the evaluation of OR projects as research. A different perspective is required. Fortunately, there is an applicable perspective that is used in a number of fields such as engineering, architecture and Information Systems, known as Design Research.

\section{What is design research?}

Design Research is a perspective on research, or a way of looking at and thinking about research. It is more than a methodology for doing research, although it includes certain methodologies. Vaishnavi and Kuechler [23] define Design Research as "a set of analytical techniques and perspectives (complementing the Positivist and Interpretive perspectives) for performing research in information systems. Design Research involves the analysis of the use and performance of designed artefacts to understand, explain and very frequently to improve on the behaviour of aspects of information systems." Hevner et al. [4] describe design research as "...fundamentally a problem solving paradigm. It seeks to create innovations that define the ideas, practices, technical capabilities, and products through which the analysis, design, implementation, management, and use of information systems can be effectively and efficiently accomplished." They are referring to Design Research in an Information Systems context, but their comments are equally applicable to Design Research in OR. March and Smith [12] add that "design science attempts to create things that serve human purposes. It is technology-oriented. Its products are assessed against criteria of value or utility — does it work? Is it an improvement?" 
Essentially then, Design Research is a process of using knowledge to design and create useful artefacts, and then using various rigorous methods to analyse why, or why not, a particular artefact is effective. The understanding gained during the analysis phase feeds back into and builds the body of knowledge of the discipline.

\subsection{What is design, and can it be research?}

Design means "to invent and bring into being" [3]. Design thus involves creating something that does not already exist in nature [23].

If design is "to invent and bring into being," what is it that is being "brought into being?" According to Simon [20], design results in the creation of Artefacts. We normally think of these artefacts as being physical things, but they can also be more abstract creations such as constructs (vocabulary and symbols), models (abstractions and representations), methods (algorithms and practices), and instantiations (implemented and prototype systems) $[4]$.

These artefacts are usually designed to meet a need, or to achieve some goal. They are the interface between the Outer Environment, the situation in which they must function, including all the natural laws that govern their functioning, and the Inner Environment, the substance and organisation of the artefact itself [20]. Design is the process of putting together an inner environment that will successfully achieve the designer's goals when the artefact functions in a specific outer environment. This process is, at heart, a trial-anderror, creative process, in which proposed solutions are iterated and enhanced until they are powerful enough to be a complete solution to the problem at hand [2].

The question that we must now ask is "Can design be research?"

Owen [18, in [23]] presents a general model for generating and accumulating knowledge, which is shown in Figure 1.

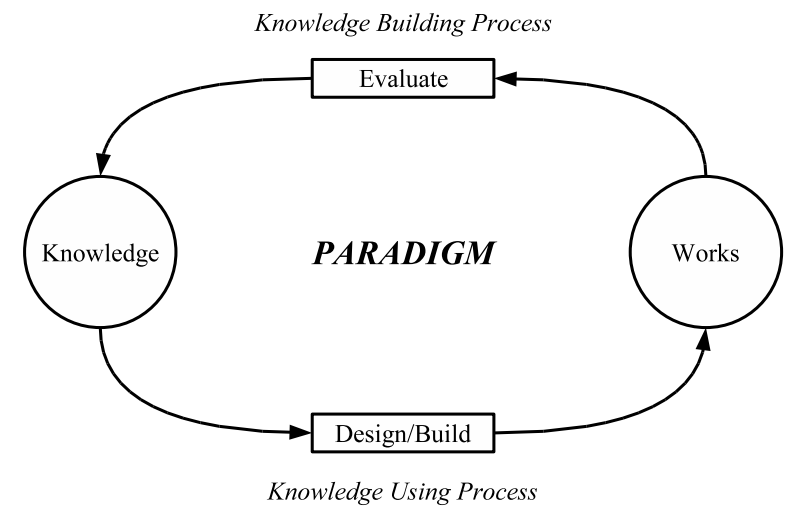

Figure 1: A general model for generating and accumulating knowledge (adapted from [23]).

In this model, knowledge is used to create works, or artefacts. The artefacts are then studied in order to build knowledge. Vaishnavi and Kuechler [23] give two example disciplines 
where this kind of knowledge generation has a long history. Architectural knowledge consists of a pool of structural designs that achieve certain goals. These have been established through the post-hoc evaluation of created artefacts, namely buildings. The early history of Aeronautical engineering is another example of a discipline that built it's knowledge base through the process of designing and building artefacts. The theoretical base of the discipline was built by analysing the results of intuitively guided designs - a process that was essentially experimentation at full scale [23].

Design then, of itself, is a knowledge using process, not a knowledge generating process, and thus cannot be considered research. However the process of using knowledge to design and create an artefact, and then carefully, systematically and rigorously analysing the effectiveness with which the artefact achieves it's goal is a knowledge generating process that can accurately be called research. This form of research is commonly called Design Research [23].

\subsection{Methodology and outputs}

As discussed earlier, traditional Natural Science is descriptive in nature, and tries to understand and explain naturally occurring phenomena. It consists of two activities, namely discovery and justification. Discovery is the creative process that generates new scientific claims, and justification is the processes of testing these claims for validity. The outputs of Natural Science are justified constructs, models and theories. Good theories are those that accurately explain and predict natural phenomena [12].

Design Research studies phenomena that are artificial rather than natural [20]. These phenomena can be both created and studied, and scientists can contribute to each of these activities. Design Research is prescriptive rather than descriptive, that is, it seeks to prescribe ways to do things more effectively. Design Research also consists of two basic activities, namely Building and Evaluating [12]. Building is also a creative process that results in new artefacts. Evaluation then tests these artefacts for their utility. The outputs of Design Research are evaluated artefacts, that is, constructs, models, methods and instantiations. Good artefacts are those that are effective, that work.

These activities and outputs are described in more detail in the remainder of this section.

\subsubsection{Methodology}

Figure 2 shows a model of the Design Research process proposed by Takeda et al. [21], which Vaishnavi and Kuechler [23] have refined and extended. Vaishnavi and Kuechler [23] describe each of the phases pictured as follows:

\section{Awareness of the Problem}

The research process begins when the researcher becomes aware of a problem. This awareness may be brought to the researcher's attention from industry or government, from new developments in technology, from reading in related disciplines, or from many other sources. The researcher will then construct a formal or informal Proposal to begin a new research effort, which is the output of this stage of the process [23]. 


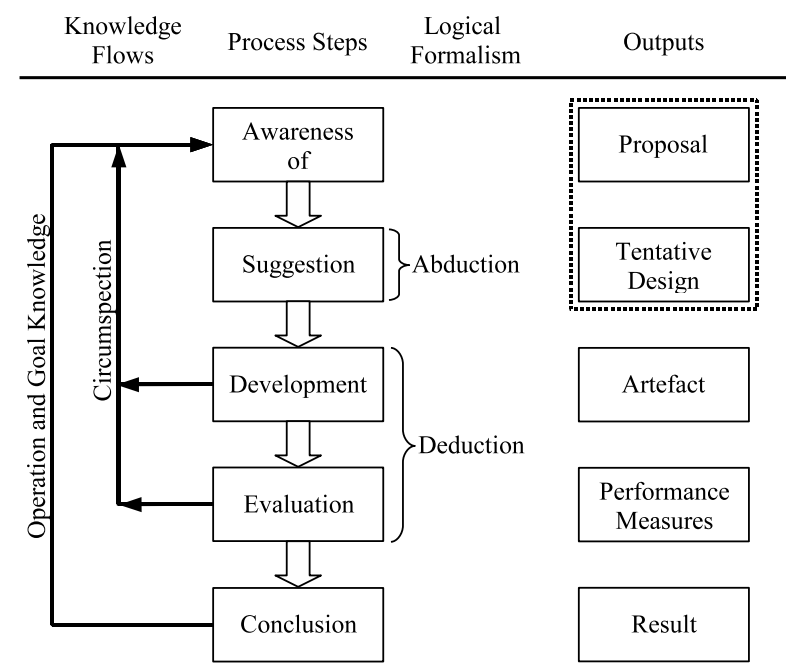

Figure 2: The general methodology of design research (adapted from [23]).

\section{Suggestion}

During the Suggestion phase, the researcher will come up with one or more Tentative Designs. These tentative designs are intimately connected to the proposal, and any formal proposal for funding will usually include at least one tentative design. If the researcher cannot formulate a tentative design, the research effort will usually be set aside. This step is essentially creative, and it is in this phase that different researchers will arrive at different tentative designs. This step is analogous to the process of theorising in Natural Science, where different researchers may arrive at different theories to explain the same set of observations [23].

\section{Development}

During this phase, the researcher will build one or more Artefacts. The techniques used will vary widely, depending on the artefacts being constructed. Some examples of artefacts are algorithms with a formal proof, software, and expert systems. The construction itself may not require any novelty beyond the state-of-practice, as the novelty is primarily in the design [23].

\section{Evaluation}

Once constructed, the artefact must be evaluated against the criteria that are either implicitly or explicitly contained in the proposal. Any deviations from the expectations must be tentatively explained. Before, and during construction, researchers will make hypotheses about how the artefact will behave. Rarely, in Design Research, are these initial hypotheses completely validated. In strict positivist research, this phase allows the researcher to determine whether the hypothesis has been falsified or not, and this marks the conclusion of the research effort [23].

In Design Research, however, this is just the beginning. The initial hypotheses are rarely discarded, but the deviations from the artefact's expected behaviour force the researchers to abduct new suggestions. The design is then also modified, often after further research in directions suggested by the unexpected behaviour [23]. 
New knowledge is produced as indicated by the Circumscription and Operation and Goal Knowledge arrows. Circumscription is a formal logical method that assumes that every fragment of knowledge is valid only in certain situations. Further, the applicability of knowledge can only be determined through the detection and analysis of contradictions $[13,23]$. This means that the researcher learns something new when things do not work 'according to the theory'. When this happens, the researcher must analyse what is going on, and why things do not work. This may be because of an incomplete understanding of the theory by the researcher, but it is more frequently because of the necessarily incomplete nature of any theory. When things do not work, and the researcher is forced to go back to the Awareness stage, new Constraint Knowledge is gained that refines the boundaries of the always-incomplete-theory that was used to design the artefact in the first place. If the researcher is able to solve the problem, this may also lead to new understanding that will modify and improve the original theory [23].

\section{Conclusion}

At some point, even though there may still be deviations in the artefact's behaviour from the, possibly multiply, revised hypotheses, the effort is considered 'good enough.' The results are then consolidated and written up. Knowledge produced is classified as firm or as 'loose-ends.' Firm knowledge are facts that have been learnt and can be applied repeatedly. Loose-ends are anomalies that cannot be explained, and frequently become the subject of further research [23].

\subsubsection{Outputs}

As shown in Figure 2, and discussed above, the outputs of the Design Research process are a Proposal, Tentative Designs, Artefacts, a set of Performance Measures and a final Result. But if Design Research is indeed research, then it must produce new understanding. What forms does this understanding take? What are the products, or outputs, of research? March and Smith [12] describe the following four outputs: Constructs, Models, Methods and Instantiations.

Constructs are the specialised vocabulary of a discipline. They allow researchers to describe concepts in their field accurately. These constructs may be highly formal, or relatively informal. Constructs arise during the conceptualisation of the problem and are refined throughout the design cycle. Since a working design (artefact) typically consists of a large number of entities and their relationships, the construct set for a design research experiment may be larger than the equivalent set for a descriptive (empirical) experiment [23].

Models are a set of statements that express relationships between constructs. They allow Design Researchers to manipulate the constructs [19]. In design activities, models represent situations as problem and solution statements. They are valuable only as far as they are useful in helping design a solution to the problem. Thus the concern of models in Design Research is utility, and not truth as in Natural Science [12].

A Method is a set of steps, an algorithm or a guideline, for performing a specific task. These steps are based on a set of underlying constructs and a model of the solution space $[12]$. 
Instantiations are the realisation of artefacts in their environment. They operationalise constructs, models, and methods. However, artefacts may be instantiated before there is a complete articulation of its underlying constructs, models and methods. Instantiations demonstrate the feasibility and effectiveness of the models and methods they contain. Instantiations are working artefacts that may be studied in many ways, leading to advancements in both Natural and Design Science [12].

Vaishnavi and Kuechler [23] add that Design Research also has as an output 'Better Theories.' These better theories may be produced in at least two ways. Firstly, many communities theorise about the methodological construction of artefacts (for example, "How to build more maintainable software"). For these communities, the construction of Design Research may be an experimental proof of method or an experimental exploration of method or both.

Secondly, artefacts may expose the relationships between their components. If these relationships are less than fully understood, and if the artefact makes these relationships clearer, either during the construction or evaluation phases, then new understanding has been produced [23].

The outputs described in this section are summarised in Table 2.

\begin{tabular}{ll}
\hline Output & Description \\
\hline Constructs & The conceptual vocabulary of a domain \\
\hline Models & $\begin{array}{l}\text { A set of propositions or statements expressing relationships } \\
\text { between constructs }\end{array}$ \\
\hline Methods & A set of steps used to perform a task how-to knowledge \\
\hline Instantiations & The operationalisation of constructs, models and methods \\
\hline Better theories & Increased understanding from studying the created artefacts \\
\hline
\end{tabular}

Table 2: The outputs of design research (adapted from [23]).

Purao [19] proposed a model of the outputs of Design Research that is shown in Figure 3.

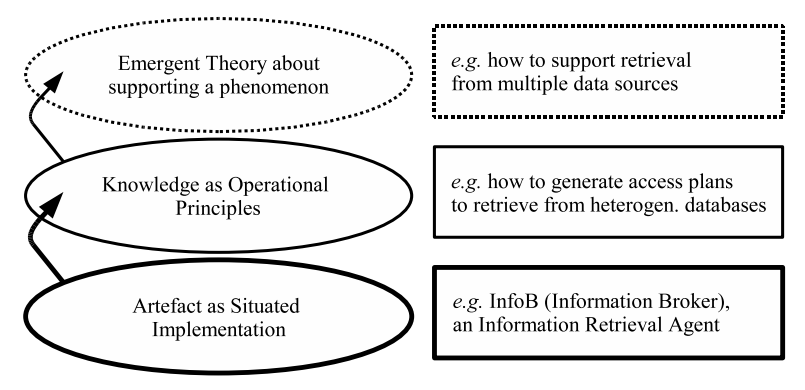

Figure 3: The outputs of design research (source: [19]). 
It has been argued [15, in [19]] that the output of Design, that is, artefacts, come to exist in a manner different from the more abstract output of Research. However, as discussed above, and shown in Figure 3, Design Research in fact produces more than just the artefacts. The artefact may be the most visible output, but it is the least important [19]. There are at least two other outputs that are more important for Design Research. Purao [19] calls the first of these "Knowledge as Operational Principles," or "reproducible knowledge." These are similar to the term Models used earlier. They are symbolic, manipulable representations of concepts and their inter-relationships. Purao calls the second important output "Emergent Theory." This is an articulation of the expected behaviour of the artefact [19].

Design Research then produces artefacts and new understanding, but how are we to understand the place of Design Research?

\subsection{How does design research compare to positivist and interpretivist research?}

It is important that researchers understand the theoretical assumptions that underpin their research. Some research communities have nearly universal agreement on the phenomena to be studied, and on the acceptable methods for researching it. Vaishnavi and Kuechler [23] call such communities paradigmatic. Other research communities have limited agreement on either the phenomena or the methods of research, and these are termed pre-paradigmatic or multi-paradigmatic [23]. In research communities that are "tightly paradigmatic" it is possible for researchers to spend their whole careers without thinking about the philosophical assumptions that underpin their research [11, in [23]]. OR is a very broad discipline, ranging from highly mathematical to very people oriented. It is thus distinctly multi-paradigmatic.

Positivist, Interpretivist and Design Research are compared in the remainder of this section under the meta-theoretical assumptions of Ontology, Epistemology, Axiology and Methodology.

\subsubsection{Ontology}

Ontology is the study that describes the nature of reality: For example, what is real and what is not, what is fundamental and what is derivative [23]?

Positivist research takes the view that there exists a single reality that is separate and independent from the researcher. This implies that the researcher and the phenomenon being observed are two separate, independent things [25].

The Interpretivist view holds that reality and the individual who observes it cannot be separated. This view stresses that an individual cannot be purely objective, and that all of a researcher's observations come through his/her own perceptions which are inextricably linked to previous experiences [25]. Reality is held to be relativist and constructed by the individual, so there can be many realities.

The Design Research view generally holds, in common with the Positivist view, that there is a single, stable underlying reality. However, Design Research by definition changes 
the state of the world by introducing novel artefacts. In common with Interpretivist researchers, Design Researchers are thus comfortable with the idea of multiple statesof-the-world, although their multiple states-of-the-world are different from the multiple realities of Interpretivist research [23].

\subsubsection{Epistemology}

Epistemology is the study that explores the nature of knowledge: For example, on what does knowledge depend and how can we be certain of what we know [23]?

Positivist researchers tend to believe that reality is separate and independent from themselves. They learn about this reality by observation. This observation is detached, dispassionate and objective. They will conclude that something is true if they have observed it $[19,25]$.

Interpretivist researchers tend to believe that they are not independent from reality, and that they construct knowledge as they live in and experience the world. They try to make sense of the world, while being aware that their sense-making is constrained by their own experiences, values and goals. Knowledge is built through social construction of the world $[25]$.

For the Design Researcher, knowing is through making. The Design Researcher learns facts and understands what they mean through an iterative process of construction and circumscription. "An artefact is constructed. Its behaviour is the result of interactions between components. Descriptions of the interactions are information and to the degree the artefact behaves predictably the information is true. Its meaning is precisely the functionality it enables in the composite system (artefact and user). What it means is what it does" [23].

\subsubsection{Axiology}

Axiology is the study of values: For example, what values does an individual or group hold and why [23]?

In a Positivist community, what is valued is Truth. Positivists seek to discover and understand the truth of the reality that is 'out there.' The truth of a theory is often measured by its predictive power.

The Interpretivist community tends to value understanding of a phenomenon. This understanding is descriptive and situated in the context.

In Design Research the community values truth and understanding, but in addition to these, manipulation and control of the environment is also valued. Relevance is also stressed. "A practical or functional addition to an area body of knowledge, codified and transmitted to the community where it can provide the basis for further exploration, may be all that is required of a successful project" [23]. 


\subsubsection{Methodology}

Methodology is the study of the methods and principles that are used in a discipline to go about building new understanding.

Positivist researchers tend to use laboratory and field experiments as well as surveys in their research. They try to gather large amounts of data that may be analysed statistically to detect underlying patterns [25]. Their methods tend to be quantitative in nature.

Interpretivist researchers tend to use qualitative methods such as case studies, ethnographic studies, phenomenographic studies and others. They try to gather thick, rich datasets that will help them understand the phenomenon in its context [25].

The methodology used by Design Researchers tends to be dualistic in nature. During the design and construction phase, the methodology may be characterised as "a creative process that involves generation of new thoughts and imaginative jumps to future possibilities" [19]. During the evaluation phase, a variety of techniques, both quantitative and qualitative, may be used to measure the effectiveness and impact of the artefact.

\subsubsection{Summary}

These philosophical assumptions are summarised by Vaishnavi and Kuechler [23] in Table 3 .

\begin{tabular}{|c|c|c|c|}
\hline $\begin{array}{l}\text { Basic } \\
\text { Belief }\end{array}$ & Positivist & Interpretivist & $\begin{array}{l}\text { Design } \\
\text { Research }\end{array}$ \\
\hline Ontology & $\begin{array}{l}\text { A single reality. Know- } \\
\text { able, probabilistic. }\end{array}$ & $\begin{array}{l}\text { Multiple realities } \\
\text { socially constructed. }\end{array}$ & $\begin{array}{l}\text { Multiple, contextually } \\
\text { situated alternative } \\
\text { world states. Socio- } \\
\text { technologically enabled. }\end{array}$ \\
\hline Epistemology & $\begin{array}{l}\text { Objective, dispassionate. } \\
\text { Detached observer of } \\
\text { truth. }\end{array}$ & $\begin{array}{l}\text { Subjective, i.e. values } \\
\text { and knowledge emerge } \\
\text { from the researcher- } \\
\text { participant interaction. }\end{array}$ & $\begin{array}{l}\text { Knowing through } \\
\text { making: objectively } \\
\text { constrained construction } \\
\text { within a context. } \\
\text { Iterative circumscription } \\
\text { reveals meaning. }\end{array}$ \\
\hline Methodology & $\begin{array}{l}\text { Observation, } \\
\text { quantitative, statistical. }\end{array}$ & $\begin{array}{l}\text { Participation, } \\
\text { qualitative. Hermeneuti- } \\
\text { cal, dialectical. }\end{array}$ & $\begin{array}{l}\text { Developmental. } \\
\text { Measure artefactual im- } \\
\text { pacts on the composite } \\
\text { system. }\end{array}$ \\
\hline Axiology & $\begin{array}{l}\text { Truth: universal and } \\
\text { beautiful; prediction. }\end{array}$ & $\begin{array}{l}\text { Understanding: situated } \\
\text { and descriptive. }\end{array}$ & $\begin{array}{l}\text { Control; creation; } \\
\text { progress (i.e. improve- } \\
\text { ment); understanding. }\end{array}$ \\
\hline
\end{tabular}

Table 3: Philosophical assumptions of three research perspectives (source: [23]).

In Design Research the philosophical perspectives shift as the research progresses iteratively through the steps outlined in Figure 2. Design Researchers begin by creating reality through constructive intervention, and then become reflective observers. Here they record the behaviour of the artefact and compare it to the predictions drawn from theory in the abductive phase. These observations, and particularly any deviations from expectations, 
are interpreted, and become the basis for new theories, and a new abductive, interventionist cycle begins [23].

Not all researchers, however, agree with these distinctions between research paradigms. For example, Weber says "For me, however, the discourse remains unsatisfactory because basically I believe it is founded on false assumptions and tenuous arguments" [25].

\subsubsection{Why is design research not design?}

Design is the process of "bringing into being," and although Design Research incorporates design, it is more than that. In typical industrial design efforts, a new product (artefact) is produced using state-of-practice application of state-of-practice techniques and readily available components. The design effort attempts to reduce the risk by removing aspects of the design that have not yet been solved. These areas that are as-yet unsolved are precisely the targets of Design Research. Design Research thus involves significant intellectual risk $[23]$.

Design Research is also more than just design, because it is not just "atheoretical tinkering" [19], but rather it is a process that uses theory to build artefacts, and then uses analytic techniques to evaluate the artefact and build better theory.

\subsection{How is design research evaluated?}

It is important to have criteria for the evaluation of any form of research. These criteria help researchers, reviewers, editors and readers understand the requirements for effective research. These criteria are dependent on the research paradigm used, so one cannot evaluate Interpretivist research using the criteria that are applicable to the Positivist paradigm.

Hevner et al. [4] articulate the following seven guidelines for the evaluation of Design Research. However, they "advise against mandatory or rote use of the guidelines. Researchers, reviewers, and editors must use their creative skills and judgement to determine when, where, and how to apply each of the guidelines in a specific research project" [4].

\subsubsection{Design as an artefact}

The result of Design Research is, by definition, a purposeful artefact, which must be described effectively so that it can be implemented and applied. These artefacts can be constructs, models, methods or instantiations. They are rarely complete, full-grown systems that can be used in practice. Rather they are innovations that define the ideas, practices, technical capabilities and products through which the analysis, design, implementation, and use of systems can be accomplished effectively and efficiently [4].

\subsubsection{Problem relevance relevance}

The purpose of Design Research is to acquire knowledge and understanding that enable the development and implementation of technology-based solutions to heretofore unsolved 
and important problems. Here, "important" is defined by the community in which the research is being conducted [4].

\subsubsection{Design evaluation}

The utility, quality, and efficacy of a design artefact must be rigorously demonstrated via well executed evaluation methods. This evaluation is what makes Design Research research, and not just "atheoretical tinkering" [19]. The criteria against which the artefact is evaluated are established by the environment and community in which the artefact will function. As with other research paradigms, evaluation of a designed artefact requires the definition of appropriate metrics and possibly the gathering and analysis of appropriate data. Artefacts may be evaluated in terms of functionality, completeness, consistency, accuracy, performance, reliability, usability, fit with the organisation, and other relevant quality attributes. A summary of possible evaluation techniques is given in Table 4.

\begin{tabular}{ll}
\hline Class & Technique \\
\hline Observational & Case Study: Study artefact in depth in business environment \\
& Field Study: Monitor use of artefact in multiple projects \\
\hline Analytical & Static Analysis: Examine structure of artefact for static qualities $(e . g$. \\
& complexity) \\
& Architecture Analysis: Study fit of artefact into technical architecture \\
& Optimisation: Demonstrate inherent optimal properties of artefact or \\
& provide optimality bounds on artefact behaviour \\
& Dynamic Analysis: Study artefact in use for dynamic qualities $(e . g$. \\
& performance) \\
\hline Experimental & Controlled Experiment: Study artefact in controlled environment for \\
& qualities (e.g. usability) \\
& Simulation: Execute artefact with artificial data \\
\hline Testing & Functional (Black Box) Testing: Execute artefact interfaces to discover \\
& failures and identify defects \\
& Structural (White Box) Testing: Perform coverage testing of some met- \\
& ric $(e . g$. execution paths) in the artefact implementation \\
\hline Informed Argument: Use information from the knowledge base $(e . g$. \\
relevant research) to build a convincing argument for the artefact's \\
utility \\
Scenarios: Construct detailed scenarios around the artefact to demon- \\
strate its utility \\
\hline Descriptive
\end{tabular}

Table 4: Design evaluation methods (source: [4]).

\subsubsection{Research contributions}

The ultimate assessment for any research is, "What are the new and interesting contributions?" Design Research can make contributions of at least three different kinds.

Most often, the contribution of Design Research is the design Artefact itself. This must enable the solution of previously unsolved problems. It may extend the knowledge base, or it may apply existing knowledge in new and innovative ways. 
Another contribution may be in the form of Foundations. These are novel, appropriately evaluated, constructs, models, methods or instantiations that extend or improve the existing foundations in the relevant knowledge base.

The creative and innovative development and use of evaluation Methods or Metrics can also provide a contribution to the body of knowledge [4].

\subsubsection{Research rigour}

Rigour is a measure of how well the research was conducted. Design Research requires the application of rigorous methods in both the construction and evaluation phases. This rigour is derived from the effective use of the knowledge base, that is, theoretical foundations and research methodologies. However, an overemphasis on rigour can lead to a reduction in relevance [4].

\subsubsection{Design as a search process}

Design is essentially an iterative search process to find an effective solution to a problem. Attempting to find the best or optimal solution is often intractable for realistic problems, so heuristic strategies are used to find feasible, good designs that can be implemented.

Problem solving can be viewed as utilising available means to reach desired ends while satisfying the laws existing in the environment. These factors are all highly dependent on the problem and its environment, and invariably involve creativity and innovation. Means are the set of actions and resources available to construct a solution. Ends represent goals and constraints on the solution. Laws are uncontrollable forces in the environment. Effective design requires knowledge of both the application domain and the solution domain. Design Research often simplifies a problem by explicitly representing only a subset of the relevant means, ends and laws, but progress is made by iteratively expanding the scope of the research and the realism and accuracy of the represented means, ends and laws [4].

The set of possible design solutions for any problem is specified as all possible means that satisfy all end conditions consistent with identified laws. When these can be formulated appropriately and posed mathematically, standard operations research techniques can be used to determine an optimal solution for the specified end conditions. Given the wicked nature of many information system design problems, however, it may not be possible to determine, let alone explicitly describe, the relevant means, ends, or laws [24].

\subsubsection{Communication of research}

Design Research must contribute to the body of knowledge. To do so, the outputs of a Design Research effort must be communicated to others. These others include other researchers who will build on the work, technical practitioners who may want to implement the solution in their environment, and managers who may need to decide whether the solution is appropriate for their situation [4]. 


\subsubsection{Summary}

These seven guidelines for evaluating Design Research proposed by Hevner et al. [4] are summarised in Table 5 .

\begin{tabular}{ll}
\hline Guideline & Description \\
\hline Design as an artefact & $\begin{array}{l}\text { Design research must produce a viable artefact in the form of a } \\
\text { construct, a model, a method, or an instantiation. }\end{array}$ \\
\hline Problem Relevance & $\begin{array}{l}\text { The objective of design research is to develop technology-based so- } \\
\text { lutions to important and relevant business problems. }\end{array}$ \\
\hline Design Evaluation & $\begin{array}{l}\text { The utility, quality, and efficacy of a design artefact must be rigor- } \\
\text { ously demonstrated via well-executed evaluation methods. }\end{array}$ \\
\hline Research Contributions & $\begin{array}{l}\text { Effective design research must provide clear and verifiable contribu- } \\
\text { tions in the areas of the design artefact, design foundations, and/or } \\
\text { design methodologies. }\end{array}$ \\
\hline Research Rigour & $\begin{array}{l}\text { Design research relies upon the application of rigorous methods in } \\
\text { both the construction and evaluation of the design artefact. }\end{array}$ \\
\hline $\begin{array}{l}\text { Design as a Search Pro- } \\
\text { cess }\end{array}$ & $\begin{array}{l}\text { The search for an effective artefact requires utilising available means } \\
\text { to reach desired ends while satisfying laws in the problem environ- } \\
\text { ment. }\end{array}$ \\
\hline $\begin{array}{l}\text { Communication of Re- } \\
\text { search }\end{array}$ & $\begin{array}{l}\text { Design research must be presented effectively both to technology- } \\
\text { oriented as well as management-oriented audiences. }\end{array}$ \\
\hline
\end{tabular}

Table 5: Design research guidelines (source: [4]).

For research to be Design Research it must produce one or more artefacts, and it must answer two fundamental questions, namely "What utility does the new artefact provide?" and "What demonstrates this utility" [4]? Hevner et al. [4, p. 91] summarise the essence of Design Research as follows: "Contribution arises from utility. If existing artefacts are adequate, then the production of new artefacts is unnecessary (it is irrelevant). If the new artefact does not map adequately to the real world (rigour), it cannot provide utility. If the artefact does not solve the problem (search, implementability), it has no utility. If utility is not demonstrated (evaluation), then there is no basis upon which to accept the claims that it provides any contribution (contribution). Furthermore, if the problem, the artefacts, and its utility are not presented in a manner such that the implications for research and practice are clear, then publication in the literature is not appropriate (communication)."

\section{Some recent examples from ORiON}

To illustrate the application of the Design Research guidelines presented in this paper, three articles from recent issues of ORiON have been analysed. The goal is not to perform a critical evaluation of the quality of the research contributions, but rather to illuminate the Design Research guidelines. The articles are:

- Joubert and Claasen [7] who develop a sequential insertion heuristic for the initial solution to a constrained vehicle routing problem. 
- Joubert and Conradie [8] who develop a fixed recourse integer programming approach towards a scheduling problem with random data.

- Krüger and Hattingh [10] who propose a two-part framework to use the Analytic Hierarchy Process and Goal Programming to allocate time to internal auditing projects.

\subsection{A sequential insertion heuristic for the initial solution to a con- strained vehicle routing problem: Joubert and Claasen}

The vehicle routing problem (VRP) is one that has received significant attention in the OR literature, and has a number of variants. This study sets out to integrate three specific variants of the problem, namely the VRP with multiple time windows, the VRP with a heterogeneous fleet and the VRP with double scheduling [7]. It appears from the paper that this study was purely an attempt to develop new theory, without application to a specific practical implementation. As this research sets out to develop new theory, it would be considered 'research' by any definition, but the paper is discussed in the following sections from the perspective of Design Research.

\subsubsection{Design as an artefact}

This paper proposes a heuristic to find an initial solution for the route that minimises the total scheduling distance to service all customers within their specified time windows. In this case the artefact is the proposed heuristic.

\subsubsection{Problem relevance}

This problem has considerable relevance to many kinds of firms that either deliver to, or collect from their customers. This relevance is evidenced by the large amount of research that has been conducted on the VRP.

\subsubsection{Design evaluation}

In order to evaluate the effectiveness of the proposed heuristic, the authors compared their heuristic to a similar heuristic that did not take into account the compatibility of time windows. They used data sets from previous research in the discipline for the customers as well as for the makeup of the heterogeneous fleet. Although the proposed heuristic did not perform better on all problem classes and instances, it gave an average improvement of $9 \%$ of the scheduling distance, as well as giving a significant improvement in the computational time required to find these solutions, across the 60 problem instances tested.

\subsubsection{Research contribution}

There are two clear contributions of this research. The first is the heuristic proposed by the authors, and the second is the programmed instantiation of this heuristic that was used to evaluate it against other heuristics. 


\subsubsection{Research rigour}

This research bases its design on previous research, specifically the Sequential Insertion Heuristic which was shown to be very successful by Joubert and Claasen [7]. The research also combines three variations of the VRP, all of which have been extensively researched separately.

\subsubsection{Design as a search process}

The heuristic proposed in this research was designed by taking a heuristic that has been shown to be successful in other circumstances, and building into it the concept of Time Window Compatibility. This allowed three variants of the VRP to be combined. The added constraints of Time Window Compatibility also reduced the computational effort required to find a solution.

\subsubsection{Communication of research}

This research shows that both distance and computational effort savings can be achieved through the use of Time Window Compatibility in cases where customers are clustered, or where longer time windows exist. The proposed heuristic is, however, only the first step in finding a near optimum solution, and the authors make some suggestions for further research. This paper speaks to a technical, research audience, and not to a managerial audience.

\subsubsection{Summary}

This research adds to the body of knowledge as it proposes a new heuristic that is an improvement over previous methods. This improvement is demonstrated by comparing the new heuristic to previously published results for alternative heuristics. If there is any weakness in this research, as measured by the seven guidelines, it is that communication of the research is focused primarily on other researchers, and not on a management audience.

\subsection{A fixed recourse integer programming approach towards a schedul- ing problem with random data: A case study: Joubert and Conradie}

In this research the authors expand previous work where they used integer programming to size and schedule the workforce of a service contractor [1]. However, after completing the previous work the authors felt that the deterministic values used for the times required for specific jobs was not a good model of reality. In this research they introduced random time requirements through a two-stage fixed recourse programme [8].

This research is an example of a case study that did not set out to develop new theory, but found that the available theory did not model reality as accurately as desired, and the researchers were thus forced to extend the theory by combining a fixed recourse model with integer programming in order to take account of the random variables. 


\subsubsection{Design as an artefact}

This research produces two artefacts, namely an integer programing model with fixed recourse, and an implementation of this model programmed in $L I N G O^{\mathbf{T M}}$.

\subsubsection{Problem relevance}

This research demonstrates its relevance as it is work that was undertaken to assist a contactor, and the employer, with the decisions they needed to make. In addition, scheduling and workforce sizing problems have been extensively studied in a number of different contexts in the OR literature.

\subsubsection{Design evaluation}

The research discussed in this article results from an evaluation of the earlier work presented in Conradie \& Joubert [1] that found that the results from the earlier study were somewhat unreliable, as they did not take into account the randomness of some of the variables. No formal evaluation of the new model is presented in this paper.

\subsubsection{Research contribution}

This research makes a contribution through the model developed, and the instantiation created. The evaluation of the earlier work that found the results somewhat unreliable also makes a contribution through providing a greater understanding of the effects of randomness on a deterministically formulated model.

\subsubsection{Research rigour}

This research builds on previous research by the same authors, and draws on a large body of literature covering workforce sizing and scheduling, as well as stochastic optimisation.

\subsubsection{Design as a search process}

This paper continues the previous research presented in [1] as part of the Circumspection and Operation and Goal Knowledge arrows in Figure 2. The authors state the problems highlighted by the previous research, and then design modifications to the model to take account of the effect of the randomness of some variables.

\subsubsection{Communication of research}

This article provides clear information primarily to fellow researchers, but in such a way that it is also accessible to a managerial audience. The article presents strong reasons to management why they should take account of the stochastic nature of the problem in the initial model design, rather than designing a deterministic model, and then relying on $a d-$ hoc recourse actions to compensate for variations that result from the inherent randomness in the problem. 


\subsubsection{Summary}

This research also makes a contribution to the body of knowledge through the model it develops and the instantiation of that model. It satisfies six of the seven guidelines. The one weakness is that, although the project was stimulated by the evaluation of previous work, no formal evaluation of the current work was presented.

\subsection{A combined AHP-GP model to allocate internal auditing time to projects: Krüger and Hattingh}

In this paper the authors develop an integrated approach to allocate time to internal auditing projects. The allocation of time to competing projects is a multi-criteria problem that includes both qualitative and quantitative aspects. In this research the Analytic Hierarchy Process (AHP) is combined with Goal Programming (GP) to distribute available hours in such a way as to minimise the risk [10]. In this paper the authors did not set out to create new theory, but they have developed a new artefact - a framework for time allocation.

\subsubsection{Design as an artefact}

This research presents a two-part framework for allocating available auditing hours in a way that minimises the risk. The first part uses the AHP to calculate an overall risk score for each project under consideration. The second part of the framework then uses GP to allocate the available auditing hours to projects in a way that minimises the overall risk. In this case the artefact produced is the framework.

\subsubsection{Problem relevance}

As organisations become larger and more complex, there is a rising need for internal auditing. Also, the legislative environment in which organisations operate is becoming increasingly complex. These factors, combined with the fact that internal auditing departments have limited resources, indicate that this kind of structured and optimised approach to allocation of time will become more and more necessary. Also, that fact that this research was tested in the internal auditing department of a South African based international gold mining company demonstrates that this problem has significant relevance.

\subsubsection{Design evaluation}

This project was evaluated by comparing the results obtained from the application of the framework to a set of five projects that were already scheduled to be conducted by the internal auditing department of the gold mining company. The utility of the framework was demonstrated by an observational case study evaluation [4], and well as using informed argument [4] to describe the views of the management of the internal auditing department. 


\subsubsection{Research contribution}

The research contributions of this study are the framework proposed by the authors, as well as their evaluation of its utility to the management of the internal auditing department.

\subsubsection{Research rigour}

The framework proposed is based on existing theory of the AHP and GP. The authors also relate their work to previous research on using the AHP in conjunction with both linear programming and goal programming, as well as research related to risk assessment. See $\S 1$ of Krüger and Hattingh [10] for details.

\subsubsection{Design as a search process}

The framework proposed in this paper was designed by first analysing the needs of the internal auditing department, and reviewing the relevant literature. The framework was then built by combining different tools (AHP and GP) to meet the needs of the two stages of the process.

\subsubsection{Communication of research}

This paper provides sufficient detail of the framework and models for other researchers and practitioners to implement and test these. At the same time the paper provides information to managers that will allow them to evaluate the benefits that could be obtained by using this framework.

\subsubsection{Summary}

Although this research did not set out to develop new theory, it satisfies all seven of the guidelines. This project is definitely an example of the Practice of OR, and is also clearly Design Research.

\section{Conclusions}

As mentioned earlier there are two components to many disciplines, including OR, namely the practice of the discipline, and research into the discipline, that seeks to advance the practice of the discipline. Obviously the research into a discipline is research, but the question posed by this paper is "Is the practice of OR research?" OR is a very broad discipline, and thus it is difficult to judge all the published articles by the same standards. It was shown that the practice of OR does not fit comfortably into the paradigm of natural research, or either of the Positivist or Interpretivist points of view. However, the Design Research perspective provides a view of research that fits well with the practice of OR. It allows a broad range of different projects to be evaluated against a set of seven objective guidelines proposed by Hevner et al. [4]. 
As shown in Table 1, more than $35 \%$ of articles published in the last 5 issuses of ORiON fall into the category of Case Studies, and the question was asked "Are these research?" Three recent articles from this category were reviewed in this article from the perspective of Design Research. In each case it was found that they met all of the seven guidelindes, although occasionally some had slight weaknesses. It is thus evident that many of the OR projects that have tradionally been seen as Practice can also be seen as Research.

Design Research thus provides a view of research that allows the practice of OR to also be seen as research. The seven guidelines presented by Hevner et al. [4] provide a clear and objective way to evaluate the quality of the research conducted in OR projects. This view of research allows OR practitioners to present their work as both practice and as research, and to ensure that the research is of a high quality. The Design Research perspective will also assist journal review panels to have a clearly articulated, objective standard by which to evaluate OR projects that are submitted for publication in their journals. This perspective is also particularly important to academics who do both research into OR and act as consultants on OR practice projects, as it provides a way for them to also present their consulting work as research.

\section{Acknowledgements}

The author would like to thank Ron Weber for his input and his encouragement that led to the writing of this article. The author would also like to thank the two anonymous referees for their useful and speedy feedback.

\section{References}

[1] Conradie DG \& JouberT JW, 2004, Workforce sizing and scheduling for a service contractor using integer programming, South African Journal of Industrial Engineering, 15(2), pp. 133-140.

[2] Glass RL, 2000, On design, The Journal of Systems and Software, 52, pp. 1-2.

[3] Grolier (Ed.), 1992, New Websters dictionary and thesaurus of the English language, Stoddart publishing, Toronto.

[4] Hevner AR, March ST, Park J \& Ram S, 2004, Design science in information systems research, Management Information Systems Quarterly, 28(1), pp. 75-105.

[5] INFORMS, 2006, What operations research is, [Online], [Cited 31 August 2006] Available from http://www.scienceofbetter.org/what/index.htm

[6] Ittmann H, 2003, Philosophy of operations research, [Personal Communication], Contactable at hittmann@csir.co.za.

[7] Joubert J \& ClaAsen S, 2006, A sequential insertion heuristic for the initial solution to a constrained vehicle routing problem, ORiON, 22(1), pp. 105-116. 
[8] JouberT JW \& CONRADie DG, 2005, A fixed recourse integer programming approach towards a scheduling problem with random data: A case study, ORiON, 21(1), pp. $1-12$.

[9] Kaplan A, 1964, The conduct of inquiry, Crowell, New York (NY).

[10] KrüGer HA \& Hattingh JM, 2006, A combined AHP-GP model to allocate internal auditing time to projects., ORiON, 22(1), pp. 59-76.

[11] Kunn T, 1996, The structure of scientific revolutions, University of Chicago Press, Chicago (IL).

[12] March ST \& Smith GF, 1995, Design and natural science research on information technology, Decision Support Systems, 15, pp. 251-266.

[13] McCarthy J, 1980, Circumscription - a form of non-monotonic reasoning, Artificial Intelligence, 13, pp. 27-39.

[14] MCLeOd WT (Ed.), 1986, The Collins paperback English dictionary, William Collins Sons and Co. Ltd., Glasgow.

[15] McPhee K, 1997, Design theory and software design, Technical Report TR 96-26, Department of Computing Science, University of Alberta, Alberta.

[16] Mouton J, 2001, How to succeed in your Master's and Doctoral Studies, Van Schaik Publishers, Pretoria.

[17] Office of Research and Innovation: Edith Cowan University, 2005, Definition of research, [Online], [Cited 2 September 2006] Available from http://www.ecu.edu.au/research/Definition_of_Research.htm

[18] Owen C, 1997, Design research: Building the knowledge base, Journal of the Japanese Society for the Science of Design, 5(2), pp. 36-45.

[19] Purao S, 2002, Design research in the technology of information systems, [Personal Communication], Contactable at sandeep-purao@psu.edu.

[20] Simon HA, 1996, The sciences of the artificial, $3^{\text {rd }}$ edition, The MIT Press, Cambridge (MA).

[21] Takeda H, Veerkamp P, Tomiyama T \& Yoshikawa H, 1990, Modeling design processes, Artificial Intelligence Magazine, 11(4), pp. 37-48.

[22] Tuckman BW, 1978, Conducting educational research, $2^{\text {nd }}$ edition, Harcourt Brace Jovanovich, Inc., New York (NY).

[23] Vaishnavi V \& Kuechler W, 2005, Design research in information systems, [Online], [Cited 14 October 2005] Available from http://www.isworld.org/ Researchdesign/drisISworld.htm

[24] Vessey I \& GLass RL, 1998, Strong vs. weak approaches to systems development, Communications of the Association for Computing Machinery, 41(4), pp. 99-102. 
[25] WeBer R, 2004, The rhetoric of positivism versus interpretivism: A personal view, Management Information Systems Quarterly, 28(1), pp. iii-xii.

[26] Wikipedia, 2006, Research, [Online], [Cited 2 September 2006], Available from http://en.wikipedia.org/wiki/Research 